Research Article

\title{
Prevalence and Antimicrobial Susceptibility Pattern of Bacteria Isolated from Mobile Phones of Health Care Professionals Working in Gondar Town Health Centers
}

\author{
Muktar Gashaw, Daniel Abtew, and Zelalem Addis \\ School of Biomedical and Laboratory Sciences, College of Medicine and Health Sciences, University of Gondar, \\ P.O. Box 196, Gondar, Ethiopia
}

Correspondence should be addressed to Zelalem Addis; addiszelalem151@gmail.com

Received 7 December 2013; Accepted 28 January 2014; Published 4 March 2014

Academic Editors: B. G. López-Valcárcel and A. R. Mawson

Copyright (C) 2014 Muktar Gashaw et al. This is an open access article distributed under the Creative Commons Attribution License, which permits unrestricted use, distribution, and reproduction in any medium, provided the original work is properly cited.

\begin{abstract}
Background. Mobile phones of health professionals can harbor various potential pathogens and become exogenous sources of infection for the patients, self, and family members. This study assessed the frequency and antimicrobial susceptibility pattern of bacteria from mobile phones of health care workers. Methods. In this crosssectional study a total of 58 health care professionals mobile phones were swabbed before and after decontamination with 70\% alcohol and assessed for contamination with bacteria. Bacterial isolation, identification, and antimicrobial susceptibility test was done as per the standard procedures. Results. About $98 \%$ of the mobile phones assessed in this study were contaminated with bacteria. Coagulase negative Staphylococci, S. aureus, and E. coli were the most frequently isolated bacteria. Decontamination with $70 \%$ alcohol significantly decreased the rate of contamination from $98.3 \%$ to $55.2 \%\left(\chi^{2}=30.17 ; P\right.$-value $\left.<0.0001\right)$. About $17 \%$ of the isolates were resistant to two drugs. Conclusion. Appropriate infection prevention measures should be taken to minimize the risk that could be associated with mobile phones since the rate of contamination was high. Decontamination with $70 \%$ alcohol was effective in minimizing bacterial contamination of mobile phones so it should be used as a decontaminant agent for these apparatuses.
\end{abstract}

\section{Introduction}

Mobile phones have become part of health professional's equipment and are used extensively for communication in a clinical setting [1]. Innovations in mobile communication have led to better patient control of diabetes and asthma and increased uptake of vaccinations by travelers reminded by short message service (SMS) [2]. However, they are seldom cleaned and are often touched during or after examination of patients and handling of specimens without proper hand washing. These cell phones can harbor various potential pathogens and become exogenous sources of infection for the patients and are also potential health hazard for self and family members $[3,4]$. Further, sharing of cell phones between HCWs and non-HCWs may directly facilitate the spread of potentially pathogenic bacteria to the community [5].

Nosocomial infections constitute a major problem globally with major social, economic, moral, and personal effects that increase morbidity and mortality of hospitalized patients [6]. It is estimated that between $5 \%$ and $10 \%$ of patients admitted to hospitals acquire HAI, but recent data suggest that this figure is on the rise [7]. The extended duration of hospital admission and extra drugs or medical management may contribute to additional cost of patient care. These factors increase the emotional stress of the patients and their families and may lead to severe disability and reduce the patients' quality of life [8].

The emergence of antimicrobial resistance is an important issue associated with nosocomial infections and most nosocomial infections are often caused by antibiotic resistant organisms $[8,9]$. Antibiotic resistance increases the morbidity and mortality associated with infections and contributes substantially to rising costs of care resulting from prolonged hospital stays and the need for more expensive drugs [10].

Different studies in different parts of the world indicated that medical equipment and mobile phones of health 
care workers are potential sources of nosocomial infections. Stethoscopes, wrist watches [11], charts of patients [8], mechanical ventilators, catheters [6], ultrasound machines, blood pressure stands, personal digital assistants, personal pagers [12-14], and so forth were found to be contaminated with different bacterial pathogens.

There are plenty of information regarding hospital acquired infection and the role of mobile phones in harboring bacteria responsible for such infections [3, 5, 7, 14-17]. But to the best of our knowledge there is no single report about similar role of mobile phones of health care professionals in health centers. From this point of view the aim of this study was to assess the rate of bacterial contamination of HCW mobile phones in different health centers around North Gondar Zone. More over the antimicrobial resistance patterns of the isolates were assessed and the efficacy of $70 \%$ alcohol in minimizing the burden of bacteria from mobile phones was also observed.

\section{Materials and Methods}

2.1. Study Area and Study Design. A cross-sectional study was conducted from February to April, 2013, at seven health centers that are found in around Gondar town, a historical town located $739 \mathrm{~km}$ far from Addis Ababa to the northwest of Ethiopia.

2.2. Sample Size and Sampling Technique. During the study period there were a total of 80 health professionals who had direct contact with patients. From these individuals 58 were volunteers to participate and were included in this study.

\subsection{Data Collection}

2.3.1. Sociodemographic Characteristics of the Participants. A self-administered questionnaire was employed to collect information about the sociodemographic characteristics (age, sex, and profession), use of mobile phones, and habit of cleaning of their mobile phones.

2.3.2. Sample Collection. Sample was collected by rolling sterile cotton swab on the keys and backs of mobile phones. From each mobile phone two swabs were taken one before disinfection and one after disinfection with $70 \%$ alcohol.

2.3.3. Isolation and Identification of Bacteria. Isolation of bacteria was made by inoculating swabs onto MacConkey agar, chocolate agar (CAP), and blood agar plates (BAP) (Oxoid, LTD). The inoculated agar plates were incubated at $37^{\circ} \mathrm{C}$ for $24-48$ hours. Preliminary identification of bacteria was made based on gram reaction, colony characteristics, haemolysis on blood agar, and changes in physical appearance in differential media. Based on the gram reactions obtained further identification of bacteria was made by a series of biochemical tests. Gram-negative bacteria were identified by using triple sugar iron agar, indole, Simon's citrate agar, lysine iron agar, urea, mannitol, and motility. Catalase, coagulase, and bacitracin sensitivity were used to identify Gram-positive bacteria [18].
2.3.4. Antimicrobial Susceptibility Test of Isolates. The antimicrobial susceptibility test of the isolates was performed according to the national committee for clinical laboratory standards (NCCLS) method using Kibry-Bauer disk diffusion test on Mulle-Hinton agar. In short the isolated bacterium was suspended in a nutrient broth and incubated for $30 \mathrm{~min}$ to make it comparable with $0.5 \%$ McFarland standard. After incubation a sterile cotton swab was dipped in to the suspension and bacteria were inoculated on to the Muller-Hinton agar. Antibiotic discs were placed by using disc dispenser and the plate was incubated for $24 \mathrm{hrs}$ at $37^{\circ} \mathrm{C}$. Results were interpreted after measuring the zone of inhibition and being compared with the standards. Escherichia coli ATCC 25922 and S. aureus ATCC 25923 were employed as strain of quality control for the antimicrobial susceptibility test [19].

2.4. Data Analysis. Data were entered and analyzed using SPSS version 16 computer software, summarized in frequencies and percentages, and presented in tables and graphs. Chisquare test was calculated to assess the presence of association between the use of $70 \%$ alcohol as a disinfectant and the burden of bacteria and $P$ value less than 0.05 was considered as statistically significant.

2.5. Ethical Clearance. The study was approved by the ethical review committee of the School of Biomedical and Laboratory Sciences before the actual data collection. Study participants were informed about the study and only volunteers were participated in the study. The participants were informed about the status of their mobile phones and were advised to use $70 \%$ alcohol as a cleaning agent.

\section{Results}

3.1. General Characteristics of the Study Participants and Their Response to Questions Related to the Use of Mobile Phones. A total of 58 health care workers (18 males and 40 females) from five health centers participated in this study. The mean $( \pm S D)$ age of the participants was $44.7( \pm 10.2)$ years, majority $(36.2 \%)$ being in the age range of $41-50$ years. Professionally majority of them were nurses $(67.2 \%)$ followed by laboratory technologists and technicians (15.2\%). The health care workers participated in this study have used mobile phones for a minimum of less than one month and a maximum of 120 months with median (IQR) of 36 (11-60) months. Majority (51.7) of them have used mobile phones for $1-5$ years.

The responses given by the participants regarding the use of mobile phones are summarized in Table 1. Accordingly $94.8 \%, 41.4 \%$, and $70.7 \%$ of the participants use cell phones in health centers, answer phone calls while attending patients, and never cleaned their cell phones before, respectively. From the study participants $70.7 \%$ thought that cell phones can carry bacteria but only $53.4 \%$ believed that mobile phones can transmit bacteria from one patient to the other. About $29.3 \%$ of the individuals carry their mobile phones with other medical equipment like stethoscope, hammer, tourniquet, and so forth. 
TABLE 1: Participants' response for questions related to the use of mobile phones.

\begin{tabular}{lcc}
\hline Question & Yes & No $(\%)$ \\
\hline Do you use your cell phone in the health center? & $55(94.8)$ & $3(5.2)$ \\
Do you use the same cell phone at home? & $44(75.9)$ & $28(48.3)$ \\
Do your colleges use your cell phone? & $24(41.4)$ & $30(51.7)$ \\
Do you answer phone calls while attending patients? & $10(17.2)$ & $17(29.3)$ \\
Do you wear gloves while answering phone calls in the health center? & $10(17.2)$ & $9(15.5)$ \\
Have you ever cleaned your cell phone in the past? & $42(72.4)$ \\
Do you clean your cell phone regularly? & $41(70.7)$ \\
Do you wash your hands after using your cell phone in the health center? & $31(53.4)$ \\
Do you wash your hands before attending your patient? & $17(29.3)$ \\
Do you think that cell phones can carry bacteria? & $34(58.6)$ \\
Do you think that cell phones can transfer bacteria from one patient to the other? & $40(69)$ \\
Do you carry stethoscope, hammer, tourniquet, and so forth with your cell phone? & $41(70.7)$ \\
Have you taken any training on infection prevention? & $35(60.3)$ \\
Do you have any guide line for infection prevention? & $49(82.7)$ \\
Do you think that mobile phones are pertinent in the health center? & $16(27.6)$ \\
\hline
\end{tabular}

TABLE 2: Frequency of mobile phones contaminated with bacteria before and after decontamination with $70 \%$ alcohol.

\begin{tabular}{lcccc}
\hline Culture result & Defore & Disinfection with 70\% alcohol & After & $\chi^{2}(P$ value $)$ \\
\hline Positive & 57 & 32 & $30.17(<0.0001)$ \\
Negative & 1 & 26 & 3 \\
\hline
\end{tabular}

3.2. Rate of Bacterial Isolation and Efficacy of $70 \%$ Alcohol. From 58 mobile phones sampled in this study 57 were contaminated with bacteria, before decontamination, and this made an isolation rate of $98.3 \%$. Only two mobile phones showed contamination with multiple bacterial species. A total of 59 bacterial isolates were identified from these mobile phones. From the isolates Gram-positive bacteria accounted for $77.9 \%$, coagulase negative staphylococci being the most frequently $(47.5 \%)$ isolated bacteria followed by S. aureus $(27.1 \%)$ and S. pyogenes (3.4\%). E. coli $(6.8 \%)$ was the most frequently isolated Gram-negative bacteria followed by $P$. stuartii (5\%). E. cloacae, K. pneumoniae, and Citrobacter species each accounted for $3.4 \%$ of the isolates (Figure 1).

When the rate of bacterial isolation was evaluated after decontamination with $70 \%$ alcohol, from the mobile phones, assessed growth was observed in 32 (55.2\%) mobile phones. In this study $70 \%$ alcohol brought a significant reduction in the rate of mobile phone contamination with $\chi^{2}(P$ value $)$ of 30.17 (<0.0001) (Table 2).

3.3. Antimicrobial Susceptibility of the Isolates. The isolated bacteria showed variable susceptibility patterns for different antibiotics tested. Ceftriaxone and ciprofloxacin were effective against $71.7 \%$ and $89.1 \%$, respectively, of the Grampositive bacteria isolated. More than half (52.2\%) and 60.9\% of Gram-positive bacteria were resistant to amoxicillin and trimethoprim-sulfamethoxazole, respectively. About $87.5 \%$ of S. aureus, $89.3 \%$ of CONS, and all S. pyogenes isolates

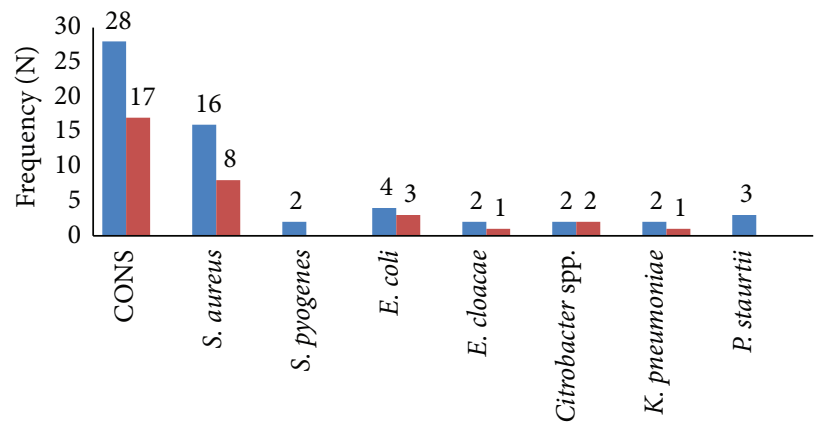

Types of bacteria isolated

- Before decontamination

- After decontamination

Figure 1: Type and frequency of bacteria isolated from mobile phones of health care workers working in Gondar health centers before and after decontamination with $70 \%$ alcohol.

were sensitive for ciprofloxacin. Among the Gram-negative bacteria $E$. coli were found $100 \%$ sensitive for ciprofloxacin, gentamycin, and trimethoprim-sulfamethoxazole. On the other hand, all isolates of E. cloacae were $100 \%$ resistant for ceftriaxone, ciprofloxacin, amoxicillin, and chloramphenicol (Table 3). Multiple antimicrobial resistances in this study ranged from resistance for two drugs up to resistance for six 
TABLE 3: Antimicrobial susceptibility pattern bacteria isolated from mobile phones of health care professional in health centers working in and around Gondar town.

\begin{tabular}{|c|c|c|c|c|c|c|c|c|}
\hline \multirow{2}{*}{ Drugs tested } & \multicolumn{8}{|c|}{ Species isolated $n(\%)$} \\
\hline & S. aureus & CoNS & S. pyogenes & E. coli & K. pneumoniae & E. cloacae & Citrobacter spp. & P. stuartii \\
\hline \multicolumn{9}{|l|}{$\mathrm{CRO}$} \\
\hline S & $10(62.5)$ & $21(75)$ & $2(100)$ & $3(75)$ & & & $1(50)$ & $3(100)$ \\
\hline I & $2(12.5)$ & $3(10.7)$ & & $1(25)$ & $2(100)$ & & & \\
\hline $\mathrm{R}$ & $4(25)$ & $4(14.3)$ & & & & $2(100)$ & $1(50)$ & \\
\hline \multicolumn{9}{|l|}{ CIP } \\
\hline S & $14(87.5)$ & $25(89.3)$ & $2(100)$ & $4(100)$ & $2(100)$ & & $1(50)$ & $2(66.7)$ \\
\hline I & $2(12.5)$ & $3(10.7)$ & & & & & & \\
\hline $\mathrm{R}$ & & & & & & $2(100)$ & $1(50)$ & $1(33.3)$ \\
\hline \multicolumn{9}{|l|}{$\mathrm{C}$} \\
\hline S & ND & ND & $2(100)$ & $3(75)$ & $2(100)$ & & & $3(100)$ \\
\hline $\mathrm{I}$ & ND & ND & & $1(25)$ & & & $1(50)$ & \\
\hline $\mathrm{R}$ & ND & ND & & & & $2(100)$ & $1(50)$ & \\
\hline \multicolumn{9}{|l|}{ SXT } \\
\hline $\mathrm{S}$ & ND & ND & ND & $4(100)$ & $2(100)$ & & $1(50)$ & $2(66.7)$ \\
\hline I & ND & ND & ND & & & & & \\
\hline $\mathrm{R}$ & ND & ND & ND & & & & $1(50)$ & $1(33.3)$ \\
\hline \multicolumn{9}{|l|}{$\mathrm{CN}$} \\
\hline S & ND & ND & ND & $4(100)$ & & $2(100)$ & $1(50)$ & $3(100)$ \\
\hline I & ND & ND & ND & & $2(100)$ & & & \\
\hline $\mathrm{R}$ & ND & ND & ND & & & & $1(50)$ & \\
\hline \multicolumn{9}{|l|}{ AMC } \\
\hline S & $6(37.5)$ & $7(25)$ & $1(50)$ & & & & $1(50)$ & \\
\hline I & $2(12.5)$ & $5(17.9)$ & $1(50)$ & $1(25)$ & $2(100)$ & & & $1(33.3)$ \\
\hline $\mathrm{R}$ & $8(50)$ & $16(57.1)$ & & $3(75)$ & & $2(100)$ & $1(50)$ & $2(66.7)$ \\
\hline \multicolumn{9}{|l|}{$\mathrm{TE}$} \\
\hline S & $8(50)$ & $15(53.6)$ & $1(50)$ & ND & ND & ND & ND & ND \\
\hline I & $2(12.5)$ & $3(10.7)$ & & ND & ND & ND & ND & ND \\
\hline $\mathrm{R}$ & $6(37.5)$ & $10(35.7)$ & $1(50)$ & ND & ND & ND & ND & ND \\
\hline \multicolumn{9}{|l|}{ S } \\
\hline S & $4(25)$ & $12(42.9)$ & $1(50)$ & ND & ND & ND & ND & ND \\
\hline $\mathrm{I}$ & $7(43.8)$ & 7 (26) & & ND & ND & ND & ND & ND \\
\hline $\mathrm{R}$ & $5(31.2)$ & $9(32.1)$ & $1(50)$ & ND & ND & ND & ND & ND \\
\hline \multicolumn{9}{|l|}{ SXT } \\
\hline $\mathrm{S}$ & $2(12.5)$ & $5(17.9)$ & & ND & ND & ND & ND & ND \\
\hline $\mathrm{I}$ & $5(31.2)$ & $6(21.4)$ & & ND & ND & ND & ND & ND \\
\hline $\mathrm{R}$ & $9(56.3)$ & $17(60.7)$ & $2(100)$ & ND & ND & ND & ND & ND \\
\hline
\end{tabular}

AMP: ampicillin; CN: gentamicin; TE: tetracycline; CIP: ciprofloxacin; C: chloramphenicol; SXT: trimethoprim-sulfamethoxazole; CRO: ceftriaxone; AMC: amoxicillin; ND: not done; CoNS: coagulase negative Staphylococci species.

drugs. Accordingly, 10 isolates (16.9\%) were resistant to two drugs and 1 isolate (1.7\%) was resistant to six drugs (Table 4 ).

\section{Discussion}

Our study demonstrated that $98.3 \%$ of the mobile phones of health care workers in the studied health centers were contaminated with bacteria. As compared to the current study lower values were reported from Saudi Arabia (43.6\%), India (40.62\%), Iran (32\%), Turkey (61.3\%), and Nigeria $(62 \%)[2-4,20,21]$. The difference observed may be attributed to the difference in implementation of infection prevention strategies as most of the studies were conducted in hospitals while our study was conducted in health centers. This can also be evidenced from this study as $41.4 \%$ and $31 \%$ of the study participants did not participate in any type of infection prevention training and they did not have any infection prevention guideline in their working area. Moreover, $70.7 \%$ of the study participants never cleaned their mobile phones which will contribute to the increased contamination rate. On the other hand, relatively similar results were reported from other parts of the world including Turkey 
TABLE 4: Frequency of multiple antimicrobial resistances.

\begin{tabular}{|c|c|c|c|c|c|}
\hline \multirow{2}{*}{ Organism } & \multicolumn{5}{|c|}{ Number of antimicrobials } \\
\hline & For 2 drugs & For 3 drugs & For 4 drugs & For 5 drugs & For 6 drugs \\
\hline S. aureus & $1(6.3)$ & $3(18.8)$ & $2(12.5)$ & $1(6.3)$ & \\
\hline CoNS & $6(21.4)$ & $3(10.7)$ & $2(7.1)$ & $4(14.3)$ & \\
\hline S. pyogenes & $2(100)$ & & & & \\
\hline E. cloacae & & & $2(100)$ & & \\
\hline Citrobacter spp. & & & & & $1(50)$ \\
\hline P. stuartii & $1(33.3)$ & & & & \\
\hline Total $(n=59)$ & $10(16.9)$ & $6(10.2)$ & $6(10.2)$ & $5(8.5)$ & $1(1.7)$ \\
\hline
\end{tabular}

(94.5\% and 90.98\%), India (95\%), and elsewhere in the world $[11,14,17,22]$.

When the types of organisms isolated are considered, despite the difference in the isolation rate, most studies had reported similar types of organisms [3, 21]. S. aureus and CoNS were the most frequently isolated organisms in those studies which is in line with our report. Klebsiella species and Enterobacter species were also isolated indicating that mobile phones of health care workers can be important sources of infection to the patients and the community at large. Similar to this result other studies have also demonstrated the presence of these bacteria as contaminants of health care workers mobile phones [2, 20]. On the other hand, other studies reported organisms like Pseudomonas species, Neisseria species, and Acinetobacter species which were not isolated in this study $[5,11,17]$.

The efficacy of decontamination with $70 \%$ alcohol was found to be $47.8 \%$. This result was lower than a study conducted elsewhere in the world which showed decontamination efficacy of $98 \%$ with $70 \%$ isopropyl alcohol [3]. Though the efficacy in our study is low still significant decrement in the rate of contamination was observed $\left(\chi^{2}=30.17\right.$; $P$-value $<0.0001)$. This suggests that the use of this decontaminating agent will have an important value in reducing bacterial colonization of health care workers mobile phones, thus decreasing transmission of the bacteria to the patients.

Bacteria isolated in this study showed variable sensitivities to different antimicrobials tested. Despite the variability observed, resistance patterns recorded in this result were higher than studies from other parts of the world $[2,20]$. Higher results in our study may be due to the poor practice of utilizing antimicrobials in safe and recommended ways. This study has also demonstrated high rates of multiple antimicrobial resistances to two drugs (16.9\%) up to six drugs $(1.7 \%)$ tested. This indicates that there will be difficulties in treating patients infected with such microorganisms as far as the rate of contamination is lowered and safety measures to prevent their transmission are contained.

\section{Conclusion}

In general from this study it can be concluded that the rate of bacterial contamination of mobile phones is very high. Even though the efficacy of $70 \%$ alcohol is low, it showed a significant decrement in the rate of bacterial contamination making it an easily accessible candidate for decontamination of mobile phones. The resistance pattern observed is also a huge challenge in treating infectious diseases with the commonly available drugs. Despite a relatively high level of knowledge about the potential role of mobile phones as bacterial reservoirs the habit of cleaning these mobile phones was poor. Regular cleaning of mobile phones by health care workers and implementation of appropriate infection prevention guideline will help in reducing the possible risks associated with mobile phones of health care workers.

\section{Conflict of Interests}

The authors announce that they have no conflict of interests.

\section{Acknowledgments}

The authors are very grateful for University of Gondar Hospital laboratory for materials and reagents support and health care workers for their voluntary participation in the study.

\section{References}

[1] J. Ramesh, A. O. Carter, M. H. Campbell et al., "Use of mobile phones by medical staff at Queen Elizabeth Hospital, Barbados: evidence for both benefit and harm," Journal of Hospital Infection, vol. 70, no. 2, pp. 160-165, 2008.

[2] G. Sepehri, N. Talebizadeh, A. Mirzazadeh, T.-R. Mir-Shekari, and E. Sepehri, "Bacterial contamination and resistance to commonly used antimicrobials of healthcare workers' mobilephones in teaching hospitals, Kerman, Iran," The American Journal of Applied Sciences, vol. 6, no. 5, pp. 806-810, 2009.

[3] U. Arora, P. Devi, A. Chadha, and S. Malhotra, "Cellphones a modern stayhouse for bacterial pathogens," JK Science, vol. 11, no. 3, pp. 127-129, 2009.

[4] I. H. Kilic, M. Ozaslan, I. D. Karagoz, Y. Zer, and V. Davutoglu, "The microbial colonisation of mobile phone used by healthcare staffs," Pakistan Journal of Biological Sciences, vol. 12, no. 11, pp. 882-884, 2009.

[5] K. Chawla, C. Mukhopadhayay, B. Gurung, P. Bhate, and I. Bairy, "Bacterial "Cell" phones: do cell phones carry potential pathogens?" Online Journal of Health and Allied Sciences, vol. 8, no. 1, pp. 1-5, 2009. 
[6] S. A. Sallam, M. A. Arafa, A. A. Razek, M. Naga, and M. A. Hamid, "Device-related nosocomial infection in intensive care units of Alexandria University Students Hospital," Eastern Mediterranean Health Journal, vol. 11, no. 1-2, pp. 52-60, 2005.

[7] M. Sadat-Ali, A. K. Al-Omran, Q. Azam et al., "Bacterial flora on cell phones of health care providers in a teaching institution," The American Journal of Infection Control, vol. 38, no. 5, pp. 404405, 2010.

[8] S. O. Teng, W. S. Lee, T. Y. Ou, Y. C. Hsieh, W. C. Lee, and Y. C. Lin, "Bacterial contamination of patients' medical charts in a surgical ward and the intensive care unit: impact on nosocomial infections," Journal of Microbiology, Immunology and Infection, vol. 42, no. 1, pp. 86-91, 2009.

[9] World Health Organization, Prevention of hospital acquired infections: a practical guide, 2nd edition, 2002.

[10] M. J. Struelens, “The epidemiology of antimicrobial resistance in hospital acquired infections: problems and possible solutions," British Medical Journal, vol. 17, pp. 652-654, 1998.

[11] Gunasekara TDCP, B. P. Kudavidanage, M. K. Peelawattage et al., "Bacterial contamination of anaesthetists hands, personal mobile phones and wrist watches used during theatre sessions," Sri Lankan Journal of Anaesthesiology, vol. 17, pp. 11-15, 2009.

[12] C. M. Braddy and J. E. Blair, "Colonization of personal digital assistants used in a health care setting," The American Journal of Infection Control, vol. 33, no. 4, pp. 230-232, 2005.

[13] A. Borer, J. Gilad, R. Smolyakov et al., "Cell phones and Acinetobacter transmission," Emerging Infectious Diseases, vol. 11, no. 7, pp. 1160-1161, 2005.

[14] D. H. Tambekar, P. B. Gulhane, S. G. Dahikar, and M. N. Dudhane, "Nosocomial hazards of Doctor's mobile phones in hospitals," Journal of Medical Sciences, vol. 8, no. 1, pp. 73-76, 2008.

[15] A. Lakshmanan, U. Sivamurugan, S. Mariappan, and K. Jagannathan, "Mobile phones: emerging threat for infection control," Sri Ramachandra Journal of Medicine, vol. 2, pp. 18-20, 2009.

[16] F. Ulger, S. Esen, A. Dilek, K. Yanik, M. Gunaydin, and H. Leblebicioglu, "Are we aware how contaminated our mobile phones with nosocomial pathogens?" Annals of Clinical Microbiology and Antimicrobials, vol. 8, pp. 1-4, 2009.

[17] O. Karabay, E. Koçoglu, and M. Tahtaci, "The role of mobile phones in the spread of bacteria associated with nosocomial infections," The Journal of Infection in Developing Countries, vol. 1, pp. 72-73, 2007.

[18] M. Chesbrougn, Manual of Medical Microbiology, Oxford Press, Britain, UK, 2000.

[19] A. W. Bauer, W. M. Kirby, J. C. Sherris, and M. Turck, "Antibiotic susceptibility testing by a standardized single disk method," The American Journal of Clinical Pathology, vol. 45, no. 4, pp. 493496, 1966.

[20] K. O. Akinyemi, A. D. Atapu, O. O. Adetona, and A. O. Coker, "The potential role of mobile phones in the spread of bacterial infections," Journal of Infection in Developing Countries, vol. 3 , no. 8, pp. 628-632, 2009.

[21] M. Sadat-Ali, A. K. Al-Omran, Q. Azam et al., "Bacterial flora on cell phones of health care providers in a teaching institution," The American Journal of Infection Control, vol. 38, no. 5, pp. 404405, 2010.

[22] J. Jayalakshmi, B. Appalaraju, and S. Usha, "Cellphones as reservoirs of nosocomial pathogens," Journal of Association of Physicians of India, vol. 56, pp. 388-389, 2008. 


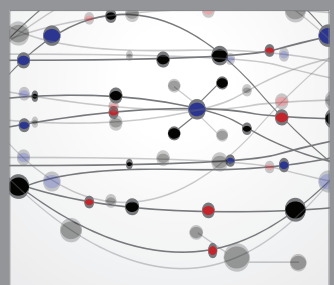

The Scientific World Journal
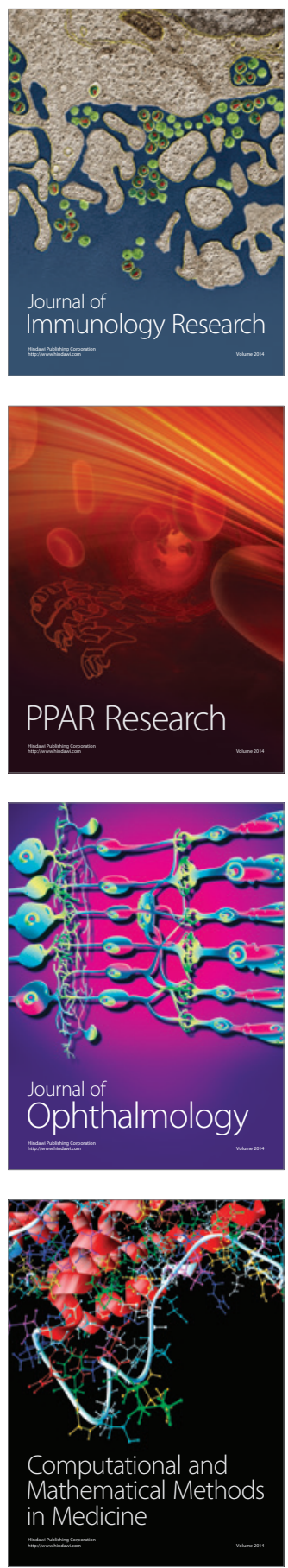

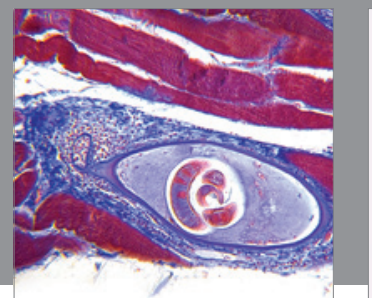

Gastroenterology

Research and Practice
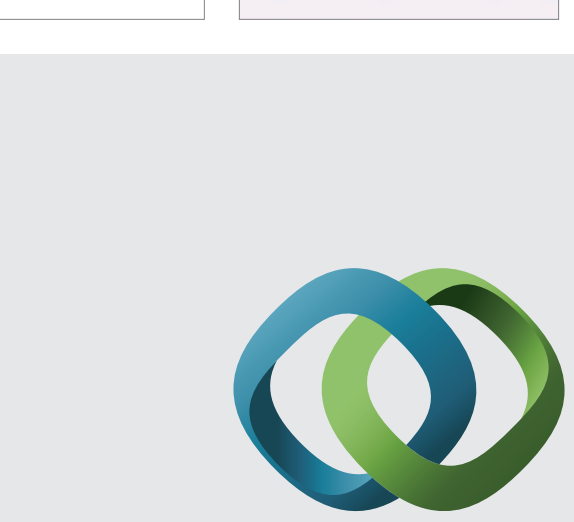

\section{Hindawi}

Submit your manuscripts at

http://www.hindawi.com
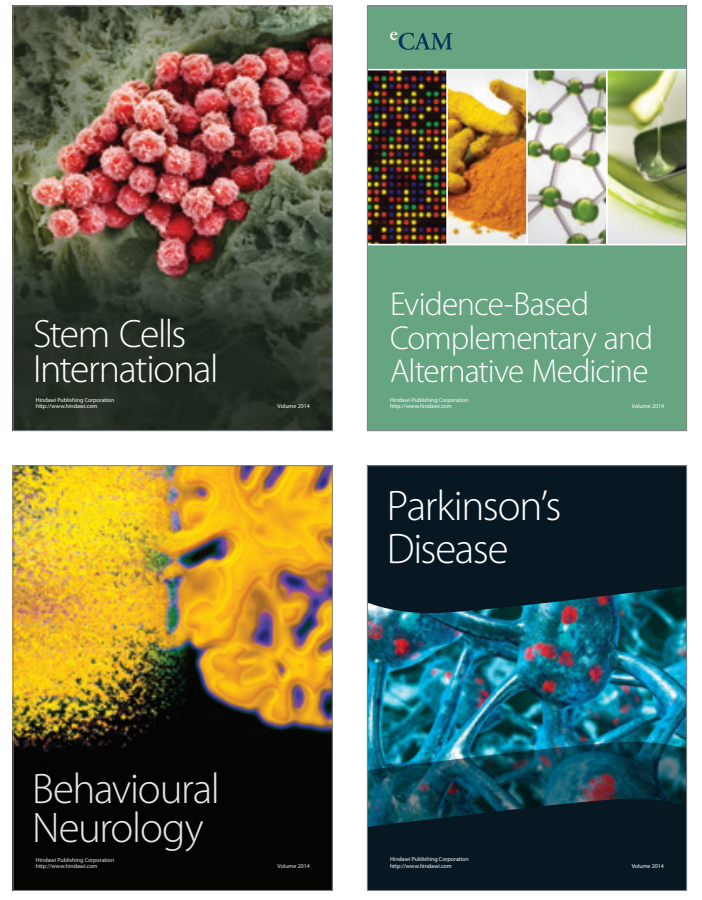
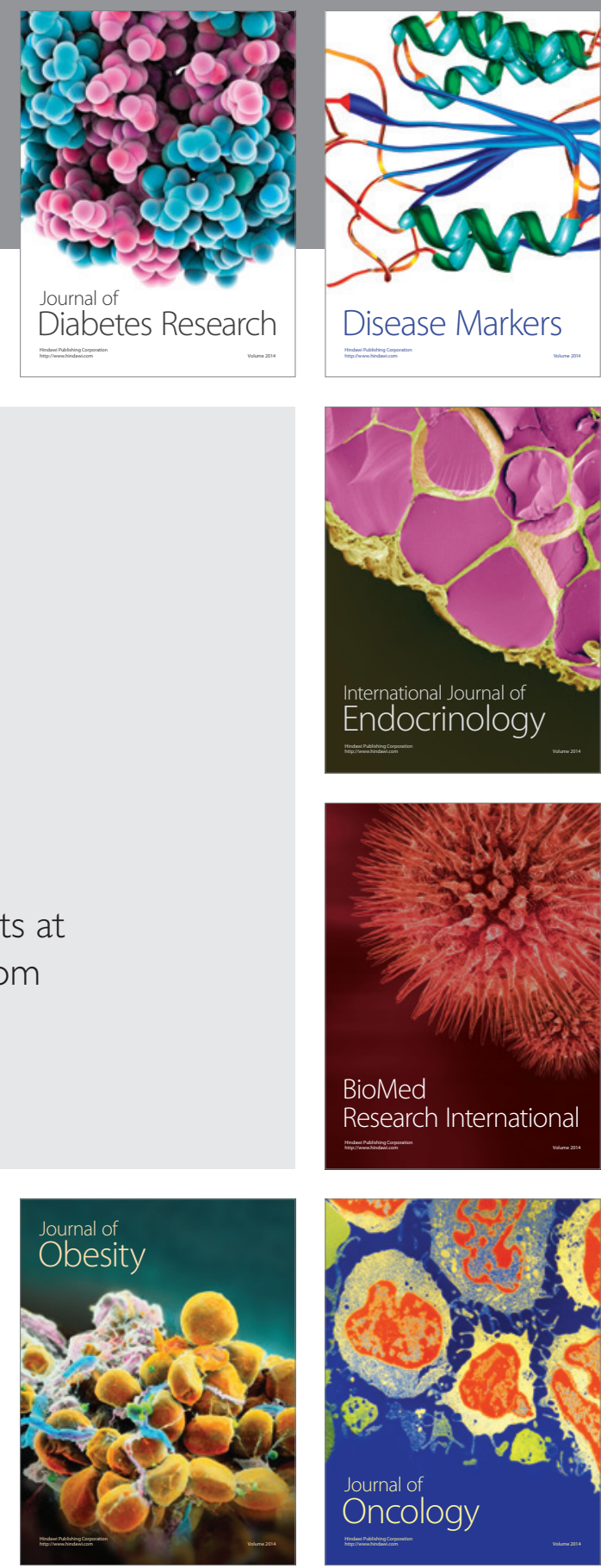

Disease Markers
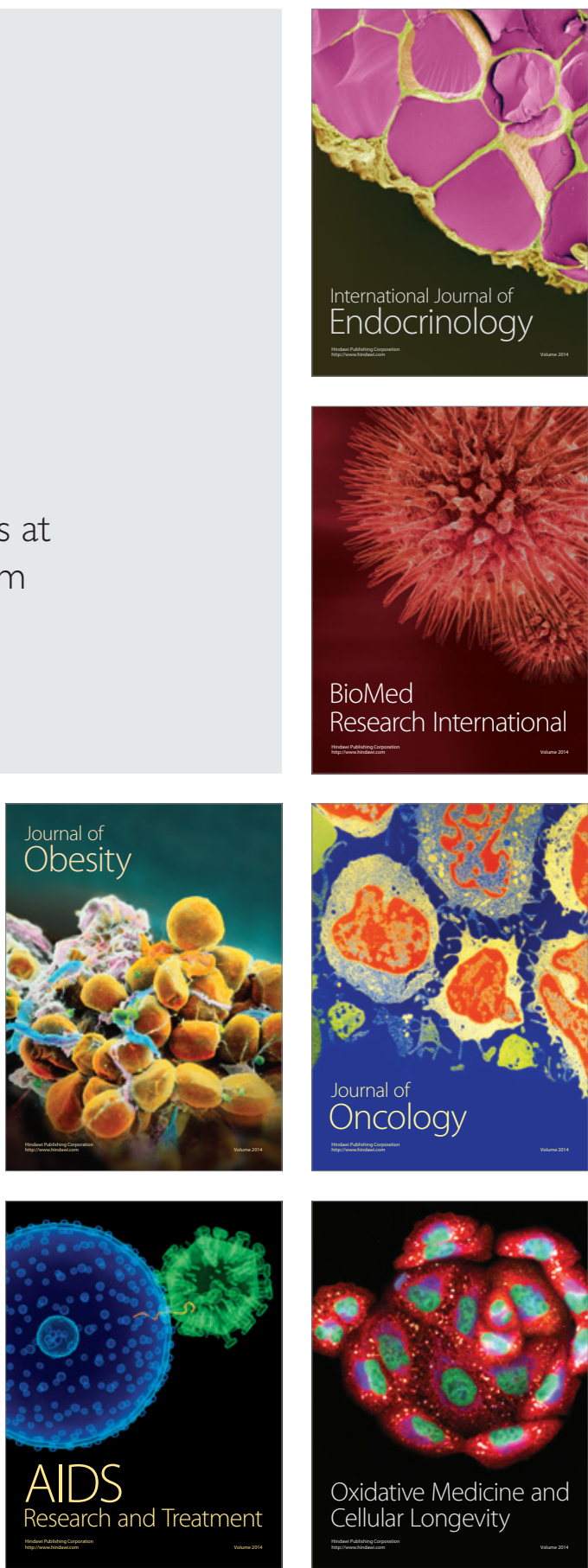